\title{
Artelogie
}

Recherche sur les arts, le patrimoine et la littérature de l'Amérique latine

5 | 2013

Femmes créatrices en Amérique latine : le défi de synthétiser sans singulariser

\section{Los cuerpos insubordinados de Elsa María Meléndez: arte y género en el Caribe}

\author{
Raquel Torres-Arzola
}

\section{OpenEdition}

Journals

Edición electrónica

URL: https://journals.openedition.org/artelogie/5741

DOI: 10.4000/artelogie.5741

ISSN: 2115-6395

Editor

Association ESCAL

Referencia electrónica

Raquel Torres-Arzola, «Los cuerpos insubordinados de Elsa María Meléndez: arte y género en el Caribe», Artelogie [En línea], 5 | 2013, Publicado el 16 octubre 2013, consultado el 20 diciembre 2021. URL: http://journals.openedition.org/artelogie/5741 ; DOI: https://doi.org/10.4000/artelogie.5741

Este documento fue generado automáticamente el 20 diciembre 2021.

Association ESCAL 


\title{
Los cuerpos insubordinados de Elsa María Meléndez: arte y género en el Caribe
}

\author{
Raquel Torres-Arzola
}

\section{NOTA DEL EDITOR}

List of illustrations in Artelogie Expo Revue
"It is important to keep in mind that one of the most important functions of ideology is to veil the overt power relations obtaining in society at a particular moment in history by making them appear to be part of the natural, eternal order of things." Linda Nochlin


Elsa María Meléndez, 'Las cirqueras' (detalle), 2006

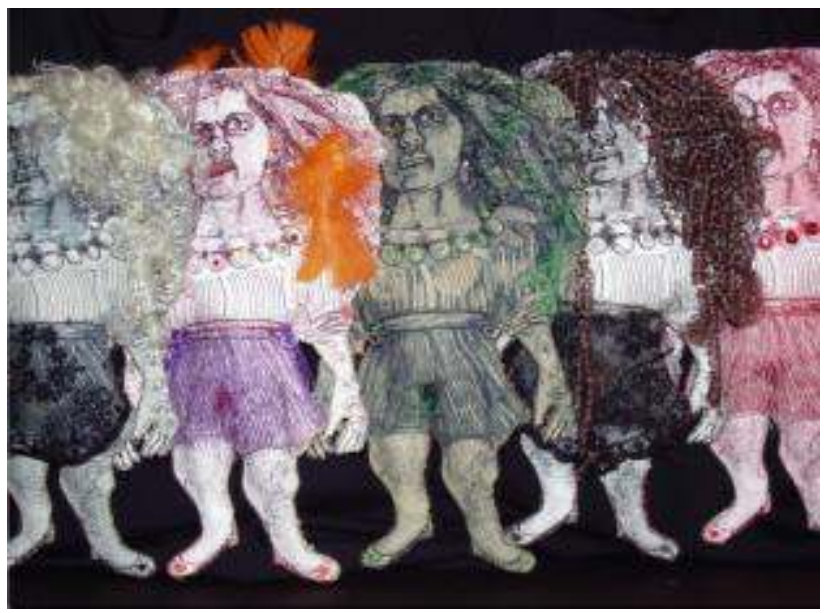

Pieza de grabado tridimensional intaglio impreso sobre papel rellenado, bordado y cosido, materiales sintéticos y caja de madera $17^{\prime} \times 26.5^{\prime} \times 7.5^{\prime}$.

\section{Introducción}

1 Después de haberse publicado varias reseñas sobre algunos aspectos culturales y sociológicos de la práctica artística de Elsa María Meléndez, llama la atención que en más de 10 años de gestión artística no se haya realizado una publicación impresa que revise su trabajo desde una perspectiva de género. En Puerto Rico, la perspectiva de género en las artes - tanto en el ejercicio historiográfico como en el ejercicio crítico ha sido mayoritariamente descartada como una teoría superada antes de haber alcanzado una mayoría de edad. Es una perspectiva tan poco reconocida y explorada dentro de la poca historiografía y crítica publicada sobre el arte puertorriqueño como se podría argumentar que lo es la labor de muchas mujeres, su quehacer y su agenda en el marco colonial que determina el espacio económico-político, en la sociedad patriarcal que comparten y en las dinámicas de historiar el arte en el país.

Según las historiadoras del arte Norma Broude y Mary D. Garrard:

Under the impetus of poststructuralist theory, the notion of a unitary feminism yielded to feminisms, whose agendas were differentiated by race, class, and ethnicity, and the very concept of gender came to be problematized as socially constructed entity. As feminist art historians began to recognize the larger scope and complexities of the power relationships that feminism interrogates and challenges, feminist art history came increasingly to situate female experience within a large framework of multiple and fluid gendered identities and positions, and to consider gender as only the one of many factors in a constantly shifting and evolving, often tensely balanced, patter of power relationships. Yet as feminist art history changed direction, splintering under the impact of postmodern gender studies into differing and contentious theoretical positions, it risked losing its original feminist political urgency. (Broude, Garrard, 2005: p. 1.)

3 Para Broude y Garrard, aún después de la mirada post-moderna y del análisis postestructuralista del ejercicio historiográfico, la cultura patriarcal continúa siendo una fuerza represiva que representa una resistencia hacia el avance de lo que ellas llaman la 'agenda de las mujeres'. Ellas postulan que las dinámicas del momento actual requieren el que se incluya de manera activa dentro de las micro-historias de disidencias estéticas 
aquellas prácticas artísticas cuyas narrativas reclaman espacios de discusión abiertos sobre los asuntos de las mujeres, dentro de toda la diversidad que ello pueda implicar:

If it is a commonplace to speak in art history of factional interactions in the political, theological, and aesthetic spheres, why should we not also trace the interaction of gender interest groups in the discourse of art? (Broude, Garrard, 2005: p. 21.)

Guillermo Villamizar, por su parte, propone que, "la decolonialidad busca estacionar a las sociedades emergentes desde una instancia que auto revisa la historia para depurar su pensamiento de los vestigios de la condición del colonizado" (Villamizar, 2012)1.

6 Haciéndose valer de la parodia como recurso, Meléndez establece en su obra narrativas de ficción. Los deseos reprimidos se permiten hacer acto de presencia en el espacio de lo visible y se establece una ardua lucha entre fantasía y realidad. La artista aborda los temas y asuntos relacionados a la identidad, los deseos, el erotismo, la sexualidad, la tradición y el rol social-conductual de las mujeres de manera abierta y directa, y los traslada al espacio de lo público como una estrategia sólida desde la cual encara el tabú y la secretividad a la que estos temas están destinados culturalmente.

Elsa María Meléndez, “La fea durmiente”, 2006

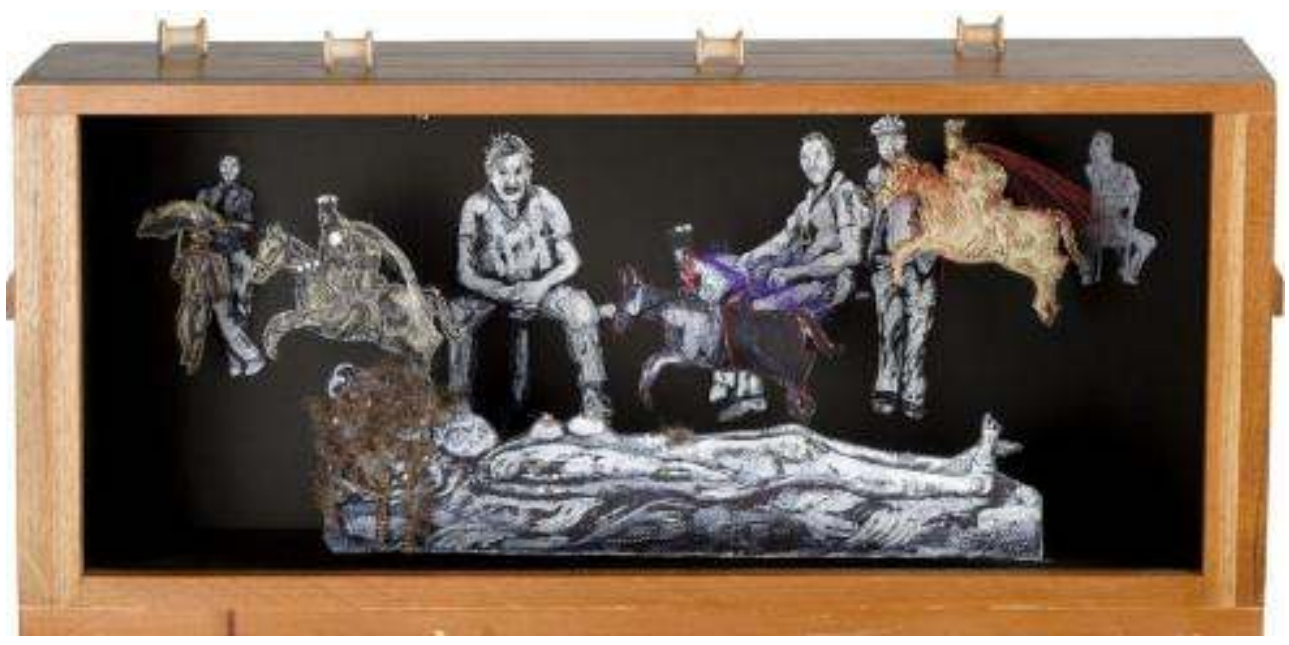

Intaglio impreso sobre papel, bordado y rellenado, materiales sintéticos, caja de madera interactiva. $7.5^{\prime \prime} \times 31^{\prime \prime} \times 12^{\prime \prime}$.

Dejándose llevar tanto por su instinto como por sus estudios en arte, Meléndez se apropia del grabado como un medio que estuvo dominado por los hombres durante gran parte de la historia del arte en Puerto Rico como un reflejo de las dinámicas de género en la historia del arte occidental. A partir de la serigrafía, la xerografía o el intaglio, Meléndez imprime sobre tela los dibujos de estos cuerpos femeninos, entre muchos otros elementos, que juntos re-crean escenas sociales diversas. Una vez impresos en la tela, la artista rellena y cose. En estas piezas, la costura, como un elemento relacionado a la tradición dentro del espacio de lo doméstico, se subvierte para ser parte del proceso de creación artística.

8 Tanto la estética como los aspectos formales de estas piezas han sido desarrollados con la intención de invitar al espectador no sólo a mirar, sino a tocar las figuras y a jugar con ellas. Esta conexión con el juego y el aspecto sensorial directo inmediatamente remonta el espectador hacia las dinámicas de la niñez, entre el aprendizaje natural y el aprendizaje institucionalizado, a la vez que yuxtapone la experiencia natural contra la 
experiencia cultural para establecer un diálogo en torno a aquellos supuestos que le dan forma a la identidad sexual femenina que hemos heredado.

Los cuerpos insubordinados de Meléndez retan de manera creativa la labor de la aguja, el medio de la serigrafía y la historia del arte al establecer un diálogo entre la historia de las mujeres y las intensas dinámicas del arte contemporáneo. En esta práctica artística se confirma la escena contemporánea como "el lugar de los fragmentos culturales [...] un dispositivo que redime los territorios del silencio después de la experiencia colonial". (Villamizar, 2012)
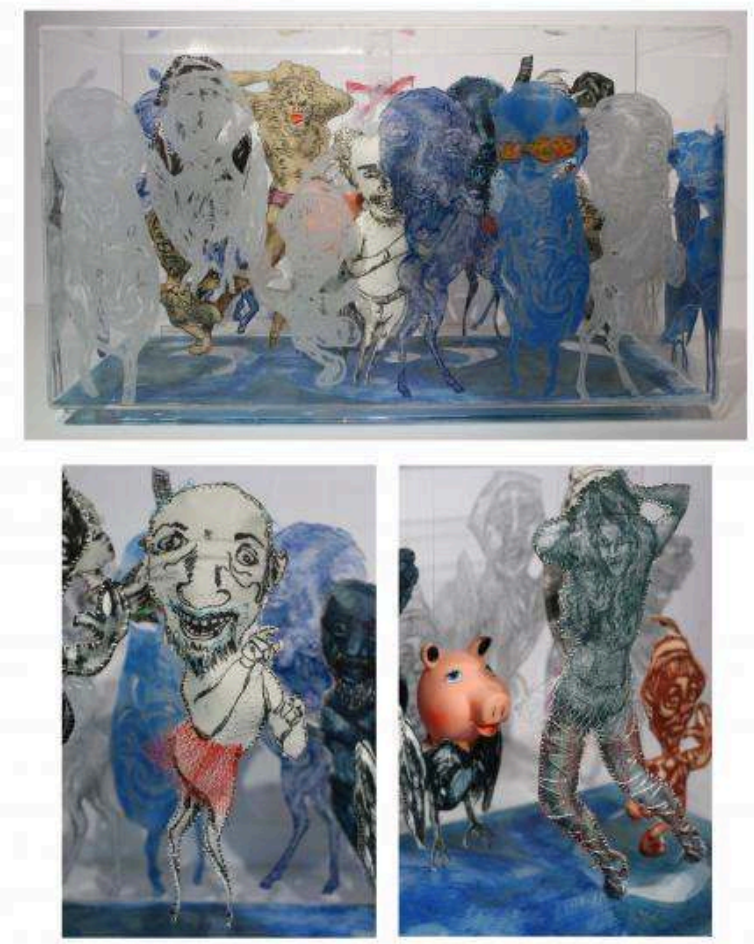

Pieza de grabado tridimensional intaglio impreso sobre papel engomado adherido a caja de acrílico, xerografía e intaglio impreso sobre papel, rellenado, bordado y cosido, otros materiales sintéticos $12^{\prime} \mathrm{x}$ $22^{\prime} \times 10^{\prime}$.

\section{Puerto Rico como el contexto}

Puerto Rico es un país caribeño en términos geográficos pero inclasificable en términos culturales. Dentro de sus fronteras geográficas, económicas, sociales y políticas cohabitan y coexisten las dinámicas, tensiones y contradicciones entre el tercer y el primer mundo, entre un estilo de consumo global y el legado de una modernidad irresuelta. Su desarrollo como país colonizado en términos políticos y neo-colonizado en sus posibilidades económicas y culturales ${ }^{2}$, aparenta depender de cuán conservadoras sean las políticas del estado colonial que lo administra, que pretende representarle y que revuelca a conveniencia los fragmentos de una identidad en constante disputa. Estas tensiones influyen sobre el pensamiento y la actuación de sus 
ciudadanos, sobre la posición de las mujeres en la sociedad y sobre la situación de todo aquel que asuma las diferencias o divergencias como opciones de vida.

Desde el estado y sus diversas representaciones en los medios masivos de comunicación, se promocionan los aspectos religiosos de la cultura y se valida al patriarcado como un orden natural inherente a la idiosincrasia del país. De este modo, se administran, se marginan y se controlan ideológicamente y con prejuiciada sutileza las prácticas relacionadas a la diversidad en lo sexual, lo cultural, lo político, lo económico y lo espiritual. Dentro de la repartición presupuestaria del país, tanto las artes como su presencia en la educación pública son áreas casi en abandono. Irremediablemente, la historiografía del arte en Puerto Rico, así como su teorización, permanecen como un ejercicio inconcluso, carente de proyección internacional y con amplias lagunas y vacíos de investigación. Peor aún, las fricciones ideológicas que sientan la pauta dentro del poco ejercicio historiográfico que sobre el arte se ha desarrollado en Puerto Rico mantienen vivo el olvido y la desmemoria, y cimientan vacíos y fracturas que se tragan prácticas artísticas completas.

En términos materiales, la gran mayoría de los artistas no vive de su práctica artística y muy pocos sobreviven por la relación que puedan tener con el mercado internacional o con los agentes relacionados a la filantropía estética (Medina, 2010). La supervivencia y presencia de la gran mayoría de los artistas en la escena depende de la autogestión, de la fundación y manejo de espacios alternativos que promuevan el taller creativo y la exhibición del arte emergente. Sin embargo, muy a pesar de que en esta actividad coinciden, co-actúan y co-existen diversos grupos de trabajo, éstos funcionan como núcleos independientes sin lazos aparentes de colaboración.

Esta situación se agrava debido a que muchas de las instituciones públicas y privadas no necesariamente representan una estructura de apoyo económica para los artistas. En Puerto Rico son los artistas y el producto de su trabajo quienes legitiman la presencia y vida de estas instituciones en la medida en que suplen una parte importante de su sostenimiento económico gracias a los frecuentes préstamos de piezas así como a las donaciones de tiempo y labor ${ }^{3}$.

Ante este vacío infraestructural y ante la caótica situación del dispositivo relacionado a la implementación de las políticas culturales en el país, una gran cantidad de protagonistas de la escena artística contemporánea en Puerto Rico practica bajo el afán de lograr una añorada y (se podría decir) urgente inclusión en el mercado y la escena global que implique un mejoramiento de sus condiciones económicas gracias a la inclusión de su trabajo dentro de la escena del arte internacional. Esta dependencia en el reconocimiento del 'otro', de que sea el 'otro' el que valide la práctica artística actual desde el sostenimiento económico $\mathrm{y}$, por ende desde la mirada occidental o primermundista y sus narrativas, provoca no solamente un ambiente de dislocación sino una multiplicidad de puntos de desencuentro para una escena artística diversa, que debería poder subsistir de manera autónoma desde su propia ejecución. Es dentro de esta confluencia de tensiones que se enmarca el trabajo de Elsa María Meléndez.

Meléndez terminó un Bachiller en Artes con concentración en grabado, dibujo y pintura en el Departamento de Bellas Artes de la Universidad de Puerto Rico, Recinto de Río Piedras en el 1997. Desde el 1999 se desempeñó como Coordinadora de Exhibiciones del Museo de Arte de Caguas, institución en la que funge como curadora a partir del 2007. Tiene a su haber estudios independientes y certificaciones en gráfica y en curaduría, así como una sustancial participación en importantes exhibiciones colectivas 
tanto en Puerto Rico como en el exterior y bien logradas exhibiciones individuales en espacios alternos y espacios institucionales.

Elsa María Meléndez, El tapón para el flujo natural del tránsito, 2006

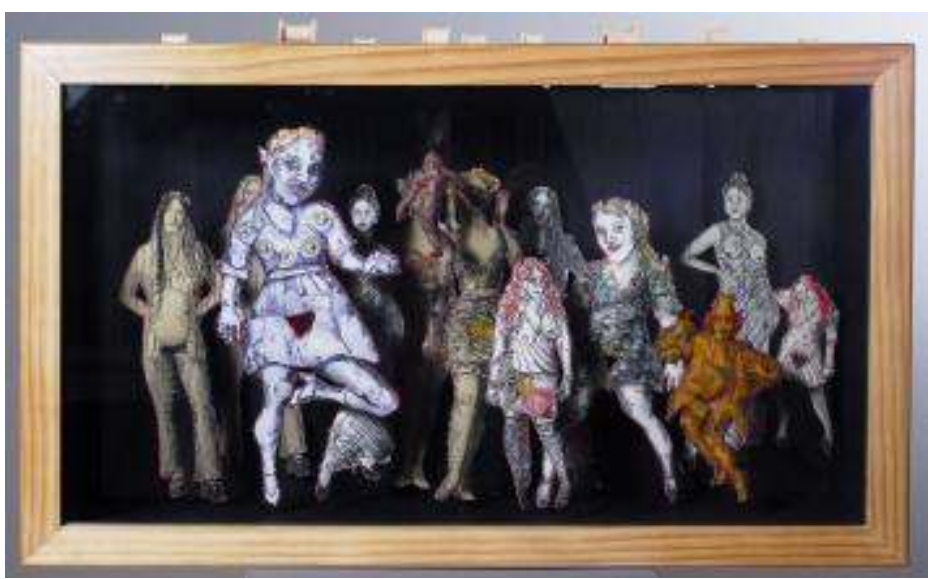

Intaglio y xerografía impreso sobre papel rellenado, cosido y bordado, caja de madera, $16.5^{\prime} \times 26.5^{\prime} x$ $7.5^{\prime}$.

\section{La práctica artística de Elsa María Meléndez}

Durante varios años intensos, Meléndez dedicó su práctica artística a la creación de una serie de cajas en madera o acrílico que operan como pequeños escenarios interactivos. En estas piezas el espectador es invitado a interactuar y colocar los personajes a su gusto dentro del pequeño escenario. Con esta participación física y directa entre el espectador y la pieza, se posibilita una variedad de narrativas dentro de un mismo relato o escena.

Interesantemente, estas cajas construidas en madera y acrílico hacen una alusión directa a la sociedad del espectáculo y nos remiten tanto a las dinámicas representativas del teatro como a las de la televisión. Los personajes que componen la narrativa en éstas piezas están ahí para ser vistos y ejercen un papel predestinado que se enriquece con el punto de vista del espectador. 
Elsa María Meléndez, El tapón para el flujo natural del tránsito, 2006, (Detalles)

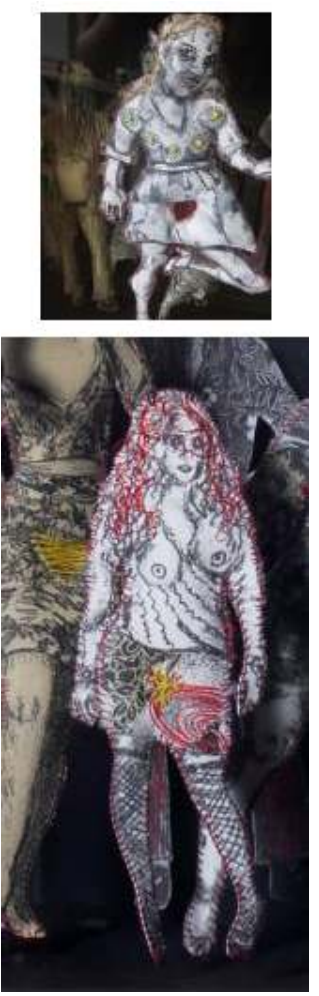

En El tapón para el flujo natural del tránsito, una diversidad de cuerpos trabajados en intaglio y xerografía sobre papel rellenado y cosido se exponen a la mirada del público. Los rostros de estas muñecas miran directamente a quien las observa y demuestran sonrientes cierto grado de complicidad y de complacencia en el acto de ser vistas. Son cuerpos femeninos cuyas características físicas van de lo real a la fantasía. El cuerpo de una mujer embarazada cuyo rostro se cubre casi en su totalidad con su propio cabello se encuentra cercano al de otra mujer cuyos detalles floridos en el traje aparentan esconder un cuerpo extraordinario de cinco senos. Otros personajes aparentan ser injertos entre leyenda y realidad. Las figuras modelan trajes escotados y faldas cortas o vestimentas que no logran ocultar las áreas erógenas. Sin embargo, cuando se observan detenidamente estos cuerpos, se puede notar que Meléndez ha sustituido el área genital por un espacio hueco de forma triangular que, en algunas de las muñecas, ha sido cosido con hilo y aguja.

Esta costura hace una alusión directa a la censura del cuerpo de la mujer y al control sobre su sexualidad. El coser el hueco en el área genital para 'ponerle un tapón', para censurarlo, podría muy bien representar una mirada desde la tradición, desde la costura como esa labor doméstica destinada a las mujeres y desde el tabú que genera el conocimiento del pecado. Esta costura hace alusión tanto a la sábana nupcial como a la mutilación genital femenina. No obstante, cuando observamos la mirada directa de las muñecas y la sonrisa provocadora que reflejan, la teoría en torno a la auto-censura se doblega ante la discusión que provoca Meléndez sobre el control de la mujer de su propia sexualidad como una herramienta de libertad y de vida propia. El "tapón para el flujo natural del tránsito" trae a colación los debates feministas iniciales entre la construcción del rol social de la mujer y su biología como un tema fundamental que se ha elaborado desde diferentes puntos de vista en el arte feminista ${ }^{4}$. 

Bourgeois con una de sus piezas bajo el brazo. Se trata de una escultura del 1968 titulada Fillette: un pene largo y erecto de testículos pronunciados. Bourgeois mira a la cámara y sonríe de manera provocadora: "Her devilish, even lewd expression, as she tickles the head of the penis, leaves little doubt that she is in control" (Nicoletta, 1992: 21-26). Las sonrisas igualmente provocadoras, unidas a la mirada directa de las muñecas que encontramos en el El tapón para el flujo natural del tránsito sugieren ese control sobre el falo ya sea cultural o institucional que ha representado dominio y censura sobre el cuerpo de las mujeres:

21 Art-making, the very creation of beauty itself, was equated with the representation of the female nude. Here, the very notion of the originary power of the artist, his status as a creator of unique and valuable objects, is founded on a discourse of gender and difference as power (Nochlin, 1998: p. 17).

Meléndez propone, desde la ironía como recurso, un rompimiento con la división binaria clásica entre "la fuerza del género masculino" y la debilidad del género femenino". Más aún, Meléndez rompe con la fantasía del cuerpo de la mujer como objeto que es poseído y se otorga a ella misma como artista el poder de seducir como parte del juego, de crear cuerpos inaccesibles, indecorosos e insubordinados desde su propia estética, insubordinados hacia el orden simbólico al que pertenecen por tradición dentro del lenguaje artístico.

Elsa María Meléndez, Haber sido más perra, 2009

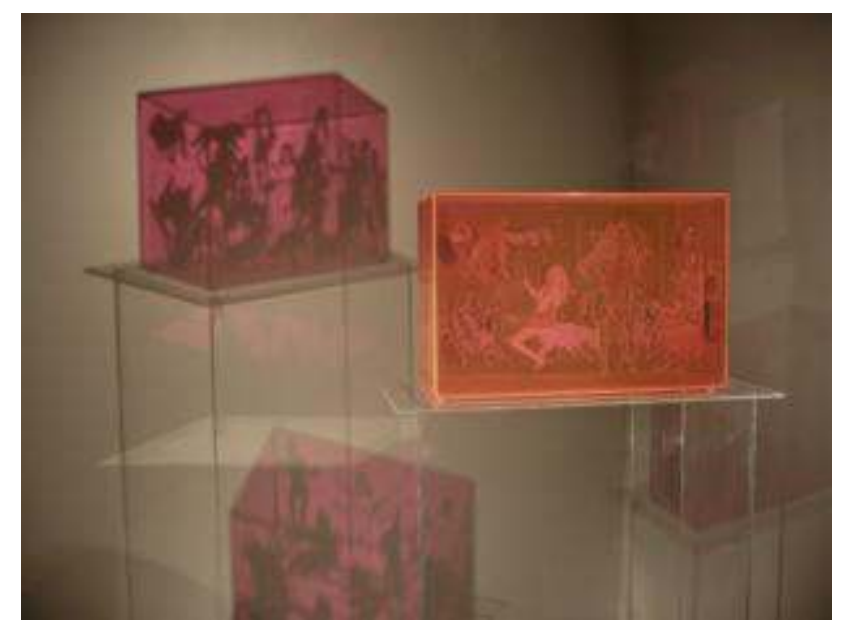

Xerografías impresas sobre papeles engomados adheridos a caja de acrílico, 14 1/2' x 22' x 9'.

Cada uno de los cuerpos que Meléndez crea es un escenario de conflictos desde el cual se desprenden imputaciones a partir del plano metafórico. El cuerpo de la mujer, como carácter semiótico que pertenece a un orden simbólico cuya estructura es patriarcal por tradición, es reclamado por Meléndez como propio para transferirle una estructura diferente. Según expone Carlos Baptista Díaz:

La pregunta ontológica de la mujer en tanto sujeto no podría ser del tipo falocéntrico: ¿qué soy yo, qué es mi cuerpo, cuál es mi sentido?; sino, expandiendo su alteridad para incorporar inclusive al otro que la ignora, ¿qué somos, cómo obra mi cuerpo, cuál es nuestro sentido?

Precisamente en Haber sido más perra tenemos esa expansión. Los cuerpos femeninos expresan una sensualidad caricaturesca y, conscientes de la mirada del otro, reclaman 
el poder, subvierten la estructura. Ellas posan divertidas ante el espectador en ropa interior, semidesnudas, desde una provocadora o traviesa sensualidad, pero conscientes de la mirada que se ejerce sobre ellas. Estas muñecas involucran a quien las mira para discutir con el espectador las condiciones en torno a su propia definición y existencia. El título Haber sido más perra evoca el deseo reprimido y su liberación, el deseo de ser más "perra", de controlar el acto sexual, provocarlo y llevarlo hacia una culminación que logre vencer la tradicional docilidad que se espera de las mujeres.

Más aún, Meléndez genera una discusión entre tradición y cultura desde la distancia generacional. Las muñecas cuyos cuerpos sexuados provocan al espectador comparten el espacio con representaciones de mujeres mayores vestidas con ropas largas que parecen ocultar un cuerpo híbrido entre mujer y animal, y cuyas miradas cuestionan su propio rol a partir de la construcción que de ellas pueda hacer quien las mira. En torno a estas interesantes representaciones nos explica la artista que:

Las imágenes realistas nunca me han transmitido caracteres ni personalidades claras. Busco transmitir personalidades, no cuerpos, busco reflejar la perversidad y los ánimos ocultos detrás del intelecto, detrás de una cara, detrás de un deseo, en ocasiones busco arrancar el pellejo. De ahí salen las bestias y los injertos que he trabajado por tiempos en mi obra. Me apasiona más la verdadera y decadente deformidad que una imagen realista tradicional y genéricamente hermosa. Tengo que decirlo, me atrae lo feo, lo crudo y complejo, juego con injertos supuestamente irreales para traer a colación una verdad, una revelación, eso, sobre todas las cosas, sale a relucir mi verdad. (TorresArzola, Meléndez, 2013)

Elsa María Meléndez, Prototipo para Haber sido más perra, 2009

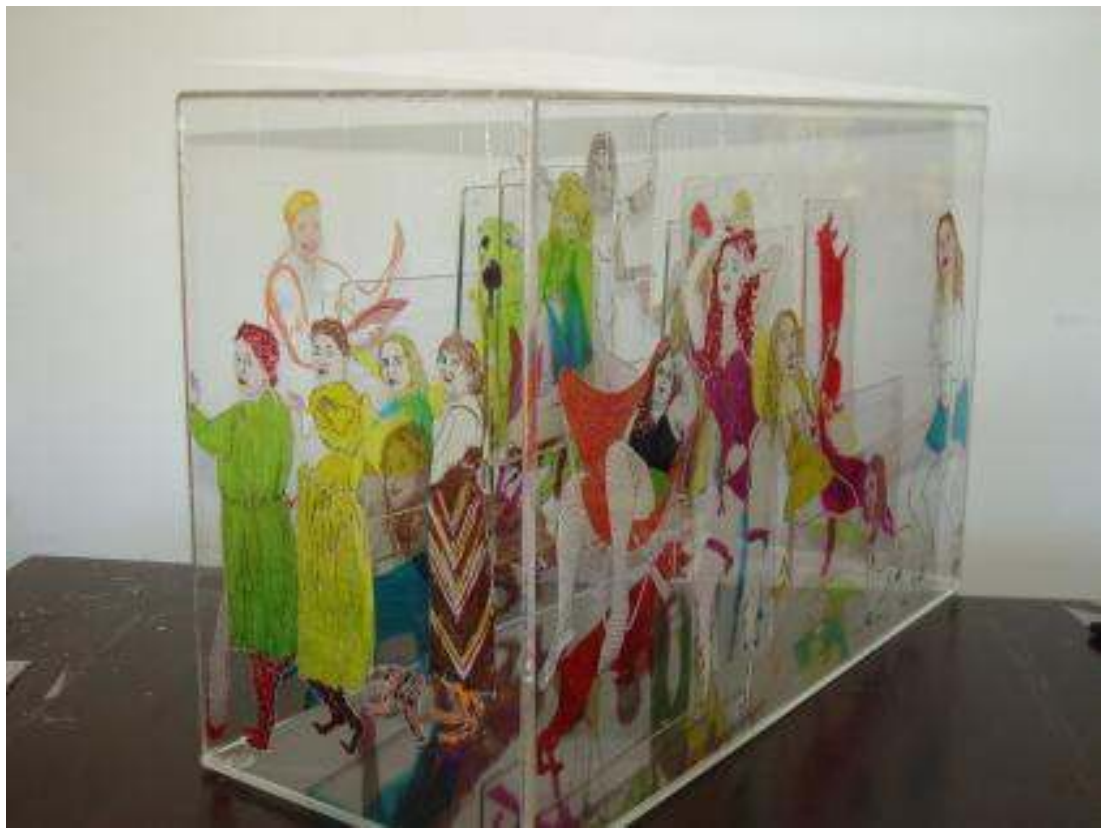

Xerografías impresas sobre papeles engomados adheridos a caja de acrílico, 14 1/2' x 22' x $9^{\prime}$

Para Marián López Fernández, el trabajo feminista en el arte a partir de la postmodernidad se interesa más bien: "en la deconstrucción de las imágenes convencionales de femineidad que el discurso de la representación sexual ha ido patriarcalizando, desconjugando para ello las marcas enunciativas y comunicativas que 
traman su espectáculo" (López Fernández, 1991-92: p. 2). Y aunque no es nuestra intención definir el trabajo de Meléndez como un arte post-moderno, sí podemos afirmar que en su obra los convencionalismos en torno a la femineidad se van deconstruyendo desde la conjugación de distintos planos metafóricos y desde la posibilidad que otorga la intensa labor manual de la artista. Esta labor le permite arrancar las figuras femeninas del orden simbólico al que pertenecen para retar no sólo los discursos a los que han sido destinados sino para retar la propia imaginación.

Las características de los cuerpos en las piezas de Meléndez han logrado establecer una diferenciación icónica que les aleja generacionalmente de las imágenes realistas que predominaron en la época de esplendor de la gráfica puertorriqueña a partir de la década de 1950. Durante este período de violentos conflictos sociales en el país, muchas de las representaciones femeninas fueron construidas desde ataduras ideológicas ligadas a los deseos de cambio social que permearon la época y para los cuales el papel de las mujeres como trabajadoras y compañeras de lucha social resultaba fundamental. La figura de las mujeres se elaboró mayoritariamente desde el punto de vista masculino, una mirada paternalista en ocasiones y tradicionalista, en otras, pero que en muchos de los casos invisibilizaron la sexualidad del cuerpo de la mujer para fortalecer su figura como matrona, pilar de la familia o líder comunitario. Meléndez de-construye ese discurso desde la parodia o la ironía sin entrar en una narrativa cerrada o íntima.

A partir de la creación de pequeños escenarios donde lo público protagoniza la discusión, la artista aporta una perspectiva donde es la propia mujer quien decide cuál es su rol y dialoga sobre la manera en que asume su propia sexualidad, o, en otros casos se critica a ella misma. Estos cuerpos insubordinados se abren a la mirada para hacer planteamientos abiertos en torno a lo reprimido como aquello que se oculta en el propio lenguaje del cuerpo $\mathrm{y}$, de paso, apuntar a la niñez como ese período donde se cuecen los conflictos en la vida adulta.

Elsa María Meléndez, La última vuelta, 2008

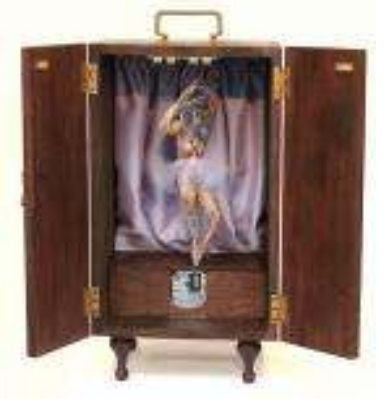

Transferencia sobre tela, rellenada y cosida, caja de madera mecánica y caja de música.17 1/2' x 9'x $91 / 2^{\prime}$.

En la pieza titulada La última vuelta, Meléndez estampa sobre tela el cuerpo de una mujer adulta. Rellena la tela y cose para crear una muñeca cuyas cualidades corporales se distancian de la bailarina o princesa que solemos encontrar en las cajas de música. Estas cajas que generalmente se regalan a las niñas, fomentan imaginarios y representaciones a partir de la creación de ciertas fantasías que involucran roles 
sociales y definiciones en torno a lo femenino desde las cualidades corporales y las características físicas, aquellas que se promueven en el mercado y se insertan en la cultura.

El cuerpo de una mujer adulta, de senos grandes, cuya vulva se puede ver por sobre el tutú del ballet, desnuda y sin zapatos da vueltas y se exhibe tristemente ante el espectador. Es la representación del cuerpo de una mujer atrapada, que se presenta como espectáculo a petición de aquel que le de cuerda al mecanismo de la caja mientras, posiblemente, se jura a sí misma que esa será 'la última vuelta'.

La delicada construcción de la caja de madera y la suavidad del telón color violeta claro en el fondo hacen referencia a la tradición y a la labor manual como baluarte. Y, de manera muy sutil, podemos encontrar alusiones al pensamiento cristiano como una doctrina que ejerce su poder sobre el cuerpo femenino y su sexualidad. La mujer, cuyos gestos faciales se distancian del placer y el disfrute, aparenta haber sido sutil pero eternamente crucificada en la Quinta posición del Ballet clásico. La pieza provoca una nostalgia profunda al hacer alusión a la niñez de la mujer encerrada en la caja como una etapa irremediablemente perdida, pero etapa al fin que da origen a esa identidad en conflicto.

Como en gran parte de su trabajo, Meléndez alude al juego. Un elemento que le permite comentar sobre el poder y la construcción de los roles. Sin embargo, lo fascinante de la pieza es su multiplicidad de lecturas. A partir de la interacción que pueda tener el espectador con la pieza, se dispara una fuerte crítica en torno al poder de un otro sobre el cuerpo y sobre la vida de esa mujer. La caja de madera hace alusión al espacio de lo privado y a la secretividad, a la cosificación de su cuerpo y de su imagen sin que se pierda la posibilidad de que, a partir del título, se haga una fuerte alusión a la muerte y a la caja como ataúd.

\section{Según describe Meléndez:}

con el solo hecho de usar la costura me refiero a mi niñez. [...] Coser para mí es un vuelco atrás, es recuerdo, rescate y añoranza de la inocencia, es también reflexión, por lo tanto es ver con ojos inocentes y objetivos la nueva realidad, quebrantada, maltrecha, descompuesta, usada, transformada y madura, es ver la vida junto a sus procesos de rehacer, deshacer y rehacerse constantemente. (Torres-Arzola, Meléndez, 2013)

La costura resulta ser en el trabajo artístico de Meléndez uno de elementos formales más importantes. Al imprimir sobre papel o tela, rellenar y coser, Meléndez extrae de la historia una labor que durante el periodo de la Gran Depresión en Puerto Rico, así como durante gran parte de la etapa industrial en el Siglo XX, representó para muchas mujeres una oportunidad de integración en la esfera laboral y una fuente de ingreso que, aunque bajo condiciones de explotación, les permitió expandir sus fronteras de lo posible. Desde la realización de la costura como una labor manual dirigida hacia la creación artística, Meléndez hace referencia a esa historia de las mujeres a la vez que se sobresale en la escena contemporánea con un lenguaje propio muy bien definido.

Según ha avanzado el desarrollo de su propuesta artística, Meléndez ha incorporado la tela como un material maleable que ha abierto sus posibilidades creativas por lo que su estética ha ido evolucionando fuertemente. En palabras de la artista: "en la tela hay un desgarramiento, como ocurre en el proceso de revelarse a uno mismo y revelarse a otros, se transforma la tela y se desgarra y se vuelve a coser, se transforma el material en otra cosa (Torres-Arzola, Meléndez, 2013) 
Elsa María Meléndez, Muñecas Country Sexuales, 2007

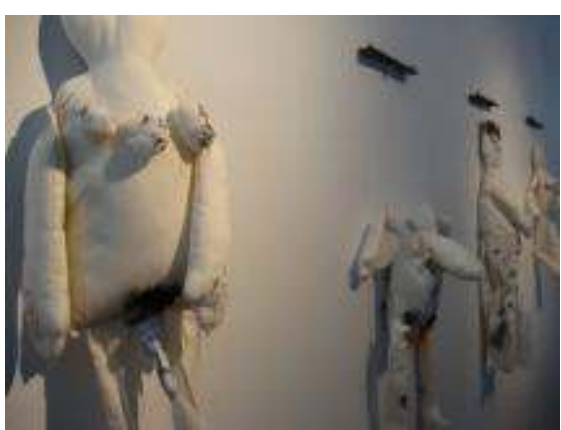

Muñecas de trapo intervenidas con xerografía, hilo, textiles y materiales sintéticos. Medidas variables.

A partir de esta maleabilidad que le ofrece la tela, Meléndez inicia en su trabajo creativo un proceso interesante desde el cual explora la de-construcción de los cuerpos a partir de sus características físicas para crear una dislocación en las relaciones de género, esto es cuerpo natural e identidad sexual, que aceptamos por costumbre. En las piezas que componen la serie Muñecas Country Sexuales, la artista presenta una variedad de cuerpos híbridos colgados en la pared y atados como marionetas a unos palos de madera. Algunas de las marionetas fueron construidas con dos rostros, otras tienen penes y vulvas, otras tienen un pene y varios senos, por mencionar ejemplos. La hibridez sexual o las múltiples identidades sexuales en la composición física de éstos cuerpos es la norma.

Estas piezas, vistas en conjunto, constituyen una serie que relaciona abiertamente la sexualidad y el erotismo con el juego en la adultez. Este acercamiento invita al espectador no sólo a develar el tabú que se ha construido en torno al placer, sino a señalar directamente la limitada función reproductiva que impone la ideología cristiana a la sexualidad, y que se promueve desde la doble moral con que la cultura se acerca a estos temas. Sin embargo, nos parece más importante la manera como la serie abre una reflexión en torno a la categoría binaria hombre/mujer y a la definición misma del término "género" como construcción discursiva.

Como afirma Judith Butler:

Los géneros 'inteligibles' son los que de alguna manera instauran y mantienen relaciones de coherencia y continuidad entre sexo, género, práctica sexual y deseo. Es decir, los fantasmas de discontinuidad e incoherencia, concebibles únicamente en relación con las reglas existentes de continuidad y coherencia, son prohibidos y creados frecuentemente por las mismas leyes que procuran crear conexiones causales o expresivas entre sexo biológico, géneros culturalmente formados y la 'expresión' o 'efecto' de ambos en la aparición del deseo sexual a través de la práctica sexual (Butler, 2007: p. 72).

Con esta pieza, Meléndez establece un diálogo con la tarea de romper con la noción de que "puede haber una 'verdad' del sexo" (Butler, 2007: p. 72). Las marionetas ponen en jaque al espectador en la medida en que cuestionan directamente la "identidad sexual definida" que traen consigo o su 'heterosexualidad institucional' (Butler, 2007: p. 72), a partir de una dislocación en el proceso de identificación que los cuerpos híbridos de las muñecas pueden provocar, más aún cuando las mismas invitan al juego sexual y a la imaginación. 
Elsa María Meléndez, El ingenio colectivo o la maldición de la cotorra, 2010

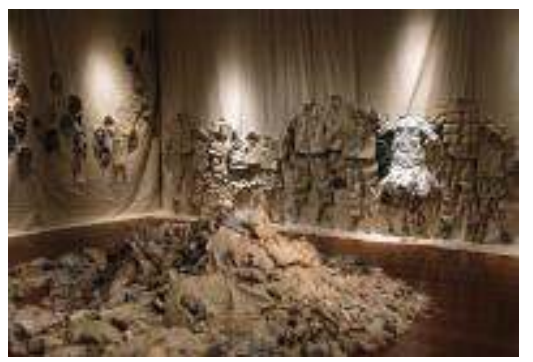

Instalación de lugar específico. Sonido, impresiones serigráficas sobre textiles rellenados y cosidos, telones, alfileres, zapatos y ropa intervenida, retazos de textiles, relleno de almohadones y gomaespuma.

Desde una poética más elaborada pero sin dejar a un lado la crudeza como estrategia, en sus piezas más recientes Meléndez explora a partir de la forma un cuestionamiento sobre las identidades desde la fragmentación casi total de los cuerpos. No obstante, en La maldición de la cotorra, la artista no sólo discute en torno a las identidades sexuales. En esta pieza, se elabora un cuestionamiento amplio sobre a las posibles construcciones del sujeto en su relación con el colectivo, como el escenario donde se reafirma la dinámica.

En la instalación La Maldición de la cotorra, Meléndez retoma la interacción con el espectador y el juego como estrategia. Sin embargo, esta instalación ocupa todo el espacio de la galería en la que se exhibe por lo que el tamaño expande las posibilidades de la caja de madera e incide en el acercamiento del público, ya sea desde un sentimiento de inseguridad o de acogimiento. La fragmentación de los cuerpos se ubica en distintos lugares de la instalación manos, cabezas, torsos y piernas. El público se ve retado a participar en la creación -ya sea física o imaginativa- de diversos personajes y a buscar su propia representación dentro de la variada propuesta de cuerpos que posibilita la pieza. Estos cuerpos fragmentados yuxtaponen una sensación de pérdida, de mutilación y de nostalgia frente al ambiente creativo y de juego que permea la instalación. 


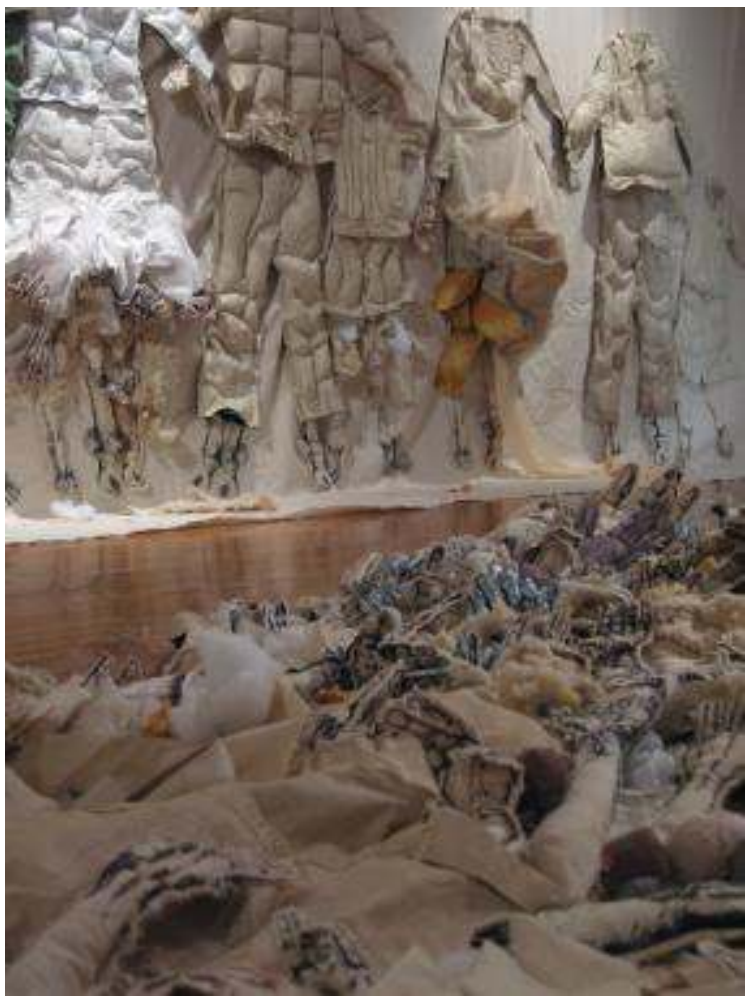

La prevalencia de una composición cromática neutral y cerrada, reforzada por la similitud de los elementos formales que componen la instalación, limita las posibilidades de los cuerpos y determinan su apariencia, predestinando sus identidades a las limitadas posibilidades que ofrece la artista. Más que permitir una diversidad de narrativas, La maldición de la cotorra limita la creación de personajes a un patrón repetitivo y estructurado de antemano. Con ello Meléndez señala al "presente colectivo" como una estructura que nos atrapa y que predetermina nuestras posibilidades de identificación en la medida en que funciona como una estructura de poder. Según nos indica la artista:

ación del material como importante recurso estético alude a los procesos de vida de cada individuo: descomposición, construcción y transformación como constantes en la cotidianidad de hacer, deshacer y rehacer el carácter humano (TorresArzola, Meléndez, 2013).

En esta instalación, la insubordinación deja de ser una característica de los cuerpos creados por Meléndez y pasa a ser una opción para el espectador quien, una vez consciente de las estructuras que le encierran, siente la necesidad y cumple el deseo de rebelarse contra la pieza al salir de la galería.

A partir de La maldición de la cotorra, la fragmentación de los cuerpos ha tomado un lugar importante en el trabajo de Meléndez. Las formas vaginales casi abstractas que se encuentran en piezas como Los que se acercaron, los que vinieron y en ¿Será el olor a queso? así como los elementos del erotismo y el juego como metáfora en La noche se traga a la pájara representan una evolución en la exploración de la forma y la poética. En su más recientes propuestas, importantes piezas como ¿Será el olor a queso ? trascienden de la estructura tangible para darle paso a la animación digital como un lenguaje rico y 
diverso en cuanto a nuevas estéticas y narrativas posibles que enriquecen los recursos de la parodia y la ironía.

47 Como propone Marián López Fernández:

Lo real, lo imaginario y lo simbólico son un entramado, antes que una sucesión de procesos de construcción de identidad. En toda representación se filtra un código cultural que potencia los rasgos, margina sus contrarios, oculta los peligros y anula los subversivos; por tanto, la representación fluctúa entre lo privilegiado y lo prohibido. Por eso, la revolución debe tomar, de aquello que desea sustituir, la imagen misma de aquello que quiere poseer, diría Barthes. Si el discurso del hombre se encuentra en la metáfora de la mujer, si la obra falocéntrica se consume despojando al cuerpo de la materialidad, habrá que deconstruir la parábola de esa metáfora para llegar a ese cuerpo. Para reconocer el cuerpo disciplinado por la abstracción y para recuperar al cuerpo deseante de su propio deseo de representación autodeterminada. Se trata de devolverle al cuerpo el derecho a la metáfora, al juego de los sentidos entre lo real, lo imaginario y lo simbólico (López Fernández, 1991-92: p. 2).

Desde la constancia y la exploración de la forma como baluarte, Elsa María Meléndez reconstruye imaginarios femeninos como parte de un juego poético en el que le da valor y vida a nuevos cuerpos y a la insubordinación.

\section{Conclusión}

Al revisar con detenimiento el trabajo artístico de la puertorriqueña Elsa María Meléndez y su práctica estética, nos percatamos de la posibilidad de confluencias que puede haber entre la de-construcción del cuerpo colonizado, la de-construcción del sujeto femenino inmerso en un proceso histórico marcado por la colonización y la deconstrucción no sólo del papel de la mujer en el arte sino de las relaciones entre artista, objeto de arte y público. Es el momento contemporáneo y sus dinámicas donde se hace posible este diálogo entre los feminismos y ciertos objetivos de las propuestas decoloniales que cuestionan y de-construyen aquellos componentes simbólicos que perpetúan la dominación sobre los sujetos, sobre los cuerpos o sobre las sociedades.

Los cuerpos insubordinados de Meléndez no sólo retan la cultura dominante desde una sexualidad abierta y desafiante sino que de-construyen el cuerpo como categoría semiótica al retar el orden tradicional donde lo biológico define el significado cultural del género, su rol y sus posibilidades sociales. A su vez, estos cuerpos insubordinados proponen una estética que rompe con el acercamiento tradicional hacia el cuerpo de la mujer en la historia del arte por lo que invitan y retan al espectador a abrirse ante nuevas posibilidades. Tanto el lenguaje de estos cuerpos sexuados como la reafirmación de ciertas características físicas celebran nuevas posibilidades en términos de la sexualidad dominante y del canon de belleza que predomina a nivel global. A partir de la reafirmación de las caderas anchas, del pelo rizado y de los senos caídos, Meléndez presenta cuerpos alejados al discurso dominante en la narrativa Occidental en la que permea la figura esbelta y perfilada. Las características físicas del elemento de la herencia africana en el Caribe hacen acto de presencia en estos cuerpos de mujeres de manera similar a como sus áreas erógenas se rebelan y reclaman ser vistas por sobre la vestimenta.

51 Al hacer uso de la costura, Meléndez libera la labor de la aguja de su rol tradicional para integrarle como elemento importante en la historia del arte en Puerto Rico. Tanto la 
descolonización de los cuerpos femeninos y su lenguaje, su semiótica y sus sexualidades así como a partir de la descolonización de la práctica artística y sus propuestas formales y estéticas Meléndez trae a la discusión una infinidad de horizontes posibles desde la experiencia del espectador. Los cuerpos insubordinados de Elsa María Meléndez se reafirman en la diferencia, en la resistencia al canon establecido y desde la ironía y la parodia retan el discurso dominante que coloniza al sujeto a partir del control sobre su sexualidad.

\section{BIBLIOGRAFÍA}

BAPTISTA DÍAZ, Carlos (2000), Hacia una teoría del cuerpo o una corporización de la teoría, Cifra Nueva, №11, Editorial Trujillo, Universidad de los Andes, Venezuela.

BROUDE, Norma \& GARRARD, Mary (Eds) (2005), Reclaiming Female Agency: Feminist Art After PostModernism, University of California Press, London.

BUTLER, Judith (2007), El género en disputa: el feminismo y la subversión de la identidad, Editorial Paidós, Barcelona.

MOHANTY, Chandra T. (1984), Under Western Eyes: Feminist Scholarship and Colonial Discourses, Boundary 2, 12 (3), 13 (1), Spring/Fall.

LÓPEZ Fernández, Marián (1991-92), Arte, feminismo y posmodernidad: apuntes de lo que viene, Arte, Individuo y Sociedad, № 4, Editorial Complutense, Madrid.

MEDINA, Cuauhtémoc (2010), Contemp(t)orary: Eleven Theses, e-flux journal, № 12. Retrieved from http://www.e-flux.com/journal/contemptorary-eleven-theses/.

NICOLETTA, Julie (1992), Louise Bourgeois's Femmes-Maisons: confronting Lacan, Woman's Art Journal 13, № 2, Rutgers University Press, NJ.

NOCHLIN, Linda (1988), Women, Art, and Power and Other Essays, Harper and Row, Publishers, US.

RICHARD, Nelly (1996), Feminismo, experiencia y representación, Revista Iberoamericana, № 176-177, University of Pittsburg, US.

TORRES-ARZOLA, Raquel \& MELÉNDEZ, Elsa María (Enero-Mayo, 2013, Conversaciones con Elsa María Meléndez vía correo electrónico [Media-file].

VILLAMIZAR, Guillermo (2012), Debate Altermodernidad/Decolonialidad, Revista Esfera Pública. Retrieved from http://esferapublica.org/nfblog/?p=22515.

\section{NOTAS}

1. Según explica Nelly Richard: "La demostración de como la identidad y el género sexuales son "efectos de significación" del discurso cultural que la ideología patriarcal ha ido naturalizando a través de su metafísica de las sustancias, es útil para romper con el determinismo de la relación sexo ("mujer") - género ("femenino") vivida como relación plena, unívoca y transparente". Para indagar más en torno al concepto 'cuerpo-naturaleza’ véase: RICHARD, 1996. 
2. La sumisión política y económica de Puerto Rico al Congreso de los Estados Unidos y su legislación sin una representación adecuada en ese cuerpo y sin el derecho a participar en los comicios electorales federales mantiene a Puerto Rico -en la práctica- dentro de las fronteras de significación de lo que es un país colonizado. Su condición de territorio no incorporado a los Estados Unidos atado a reglamentaciones federales que limitan sus posibilidades legales para realizar tratados económicos internacionales le convierte en un blanco de la inversion extranjera $\mathrm{y}$, por consecuencia, en un país cuya experiencia económica y-podríamos decir cultural- se limita a la del consumidor. Esta situación tiene un efecto directo y profundo en la idiosincrasia social y política del país.

3. Gran parte de los museos e instituciones culturales en Puerto Rico no necesariamente cuentan con un presupuesto que brinde un apoyo económico para aquel artista cuyas piezas forman parte de una exhibición, por lo que el artista tiene que prestar las piezas al museo y también sufragar los gastos de transporte e instalación. Así mismo, las instituciones privadas que promueven programas de residencia para los artistas no necesariamente asignan un presupuesto para la creación o la compra de materiales, ni mucho menos para gastos de alimentación o de viaje. Sin embargo, muchos artistas brindan talleres de manera gratuita para el público general que visita estas instituciones, y participan continuamente de conferencias, conversatorios y talleres.

4. Para la década del 1970 el movimiento feminista debatió intensamente en torno a la humanidad como una identidad y al valor que precede la identidad de género definida por una categoría biológica. Algunas feministas como Simone de Beauvoir apuntaron directamente al cuerpo como una "estructura orgánica" capaz de limitar la libertad de acción y de creación de las mujeres en honor a la "perpetuación de las especies". Para referencias en torno a esta discusión en la historia del arte feminista ver el trabajo de Mary Kelley, Jaroslaw Kozlowski, Ewa Partum y Zofia Kulik, Judy Chicago y Hannah Wilke.

\section{RESÚMENES}

Cuando observamos detenidamente el trabajo artístico de Elsa María Meléndez encontramos con frecuencia e insistencia representaciones no convencionales de cuerpos femeninos que retan directamente y sin pudor la construcción tradicionalista que en torno a las mujeres abunda en la historia del arte. Son cuerpos que no sólo asumen la diversidad como característica física sino las sexualidades en conflicto como sus más sólida particularidad discursiva.

Haciéndose valer de la parodia como un recurso, Meléndez logra establecer en su obra y con claridad narrativas de ficción desde las cuales los deseos reprimidos se permiten hacer acto de presencia en el espacio de lo visible. La artista aborda temas y asuntos relacionados a la identidad, la sexualidad, el erotismo, la tradición y el rol social-conductual de las mujeres de manera abierta y directa y los mueve al espacio de lo público como una estrategia sólida desde la cual encara el tabú y la secretividad a la que estos temas están tradicionalmente destinados.

Los cuerpos insubordinados de Meléndez retan de manera creativa la tradición de la labor de la aguja, el medio de la serigrafía y la mismísima historia del arte al establecer un diálogo entre la historia de las mujeres y las intensas dinámicas del arte contemporáneo.

Lorsqu'on observe attentivement l'œuvre d'Elsa Meléndez, trop souvent on trouve des représentations non conventionnelles du corps féminin qui contestent, ouvertement et sans pudeur, la construction traditionaliste qu'on voit couramment à travers l'histoire de l'art. Ce sont 
des corps qui non seulement assument la diversité des apparences physiques, mais ils présentent aussi sexualités conflictuelles comme leur plus forte caractéristique discursive.

Utilisant la parodie comme outil, Meléndez mets en scène des narrations fictionnelles où la sexualité rend visible les désirs opprimés. L'artiste aborde thèmes et questions liées à l'identité, la sexualité, l'érotisme, la tradition et le rôle socio-comportemental des femmes dans un dialogue ouvert et direct, en leur menant à l'espace public comme une stratégie solide qui fait face au tabou, et au secret où ces questions sont traditionnellement destinées.

Les corps désobéissants de Meléndez défient avec créativité la couture traditionnelle, la technique de sérigraphie, et l'histoire de l'art elle-même pour établir un dialogue entre l'histoire des femmes et les intenses dynamiques de l'art contemporain.

\section{ÍNDICE}

Palabras claves: Meléndez (Elsa María), cuerpos insubordinados, feminismo, Puerto Rico, Caribe, arte contemporáneo

Mots-clés: Meléndez (Elsa Maria), corps révoltés, féminisme, Puerto Rico, les Caraïbes, art Contemporain

\section{AUTOR}

\section{RAQUEL TORRES-ARZOLA}

Conferenciante Departamento de Bellas Artes Universidad de Puerto Rico - Estudiante Graduada San Francisco Art Institute

raqueltorresarzola[at]gmail.com 